\title{
Characteristic Appearances of Nodular Fasciitis on High-Resolution Ultrasonography: With Vasculature Status from A Lesion-Located Perspective
}

\author{
Kazumi Fujioka* \\ Department of Dermatology, Fujioka Dermatological Clinic, Tokyo, Japan \\ *Corresponding author: Kazumi Fujioka, MD. PhD. Department of Dermatology, Fujioka Dermatological Clinic, 1-35-10, \\ Tamagawa, Ota-ku, Tokyo, Japan
}

\section{ARTICLE INFO}

Received: 慧 August 14, 2019

Published: 幽 August 20, 2019

Citation: Kazumi Fujioka. Characteristic Appearances of Nodular Fasciitis on High-Resolution Ultrasonography: With Vasculature Status from A LesionLocated Perspective. Biomed J Sci \& Tech Res 20(4)-2019. BJSTR. MS.ID.003490.

Keywords: Subcutaneous Nodular Fasciitis; Intradermal Nodular Fasciitis; Intramuscular Nodular Fasciitis; Color Doppler Ultrasonography; Cytogenetic Nature; Dermis

\begin{abstract}
As nodular fasciitis (NF) is benign and self-limited, the clinical, ultrasonographic and pathological appearances have been described as mimicking sarcoma. NF has been cytogenetically considered as a novel model of transient neoplasia induced by MYH9-USP6 (myosin heary chain 9-ubiquitin -specific peptidase 6) gene fusion. It has been reported that the strong overexpression of USP6 under MYH9 promoter appears to drive tumorigenesis. The similar cytogenetic nature has been also demonstrated in both subcutaneous NF and intradermal type. The author previously described that the presentations of clinical, ultrasonographic and pathological features of NF are attributed to the cytogenetic nature, having the high proliferative growth and involutional nature. The author has also reported the characteristic power Doppler Ultrasonography (US) imaging of $\mathrm{NF}$ from a dermatological perspective and suggested that blood low signal is more detectable in intradermal NF than that in subcutaneous type. In this article, the current knowledge of the characteristic vasculature status in NF was reviewed from a lesion located perspective. The author will suggest that intradermal NF and subcutaneous NF, especially in a superficial location, close to or in contact with the dermis may show blood flow signal on color and power Doppler US.
\end{abstract}

\section{Introduction}

$\mathrm{NF}$ is a benign soft tissue tumor of fibroblastic/myofibroblastic differentiation that was first reported in 1955 by Konwaler et al. [1]. Goodlad et al. [2] stated the first case of intradermal nodular fasciitis (NF), very rare entity in 1990. Even though nodular fasciitis (NF) is benign and self-limited, the clinical, ultrasonographic and pathological appearanaces have been described as mimicking sarcoma. Erickson-Johnson et al. [3] first have reported that $\mathrm{NF}$ is as a novel model of transient neoplasia induced by MYH9USP6 gene fusion. A clear relation between NF and a recurrent genetic abnormality has been established in fluorescence in-situ hybridization (FISH) analysis [3-8]. It has been also demonstrated that both subcutaneous NF and intradermal type show the similar cytogenetic nature [4]. In previous article, the author described that the presentations of clinical, ultrasonographic and pathological features of NF are caused by the cytogenetic nature, having the high proliferative growth and involutional nature [9]. The author has also reported characteristic power Doppler sonographic imaging of NF from a dermatological perspective and indicated that intradermal type may more remarkably show blood flow signal on power Doppler US than subcutaneous one [10]. It has been also suggested that dermal layer contains rich capillary vessels $[11,12]$. In this article, the current knowledge of color Doppler US features in NF will be reviewed from a lesion seated viewpoint in detail.

\section{Nodular Fasciitis}

NF occurs most typically in the upper extremities, the trunk, and the head and neck. It usually presents between the ages of 20 and 40 years, often with tenderness. NF shows a peculiar clinical behavior characterized by rapid growing, self-limited, spontaneous regression after a few weeks; this peculiar clinical presentation has come to cytogenetic attention. The majority of NF arise in the subcutaneous tissue. They sometimes extend from the surface of underlying fascia, and a smaller proportion are intramuscular or periosteal location. NF is 3 to 10 times more frequently found in the subcutaneous tissue than at other regions [13]. While, intradermal 
$\mathrm{NF}$ is a very rare entity that histological finding showed an illdefined intradermal spindle cell tumor, which extended from the dermo-epidermal junction down to superficial subcutis [2]. NF can be histologically classified into 3 subtypes: myxoid, cellular, and fibrosis. There is a relationship between the age of mass and histological components. The younger lesions predominantly composed of the myxoid component, while a fibrous feature predominate in older lesions. The combination of myxoid and cellular components or a coexistence of cellular and fibrous types is shown $[13,14]$.

\section{Ultrasonographic Anatomy}

DERMUS (Dermatologic Ultrasound), the international working group, was formed and provided the guidelines for performing dermatologic ultrasound examinations [15] and proposed for an assessment training program [16]. The minimum frequency recommended for performing dermatologic examinations by DERMUS was $15 \mathrm{MHz}$ [16]. We usually perform US examinations for dermatologic lesions with a high-resolution, broad-band (5MHz$18 \mathrm{MHz}$ ) linear transducer (Nobulus Hitachi, Ltd.Tokyo, Japan). We have reported several studies concerning the dermatologic field [9-11, 17-22]. Mandava et al. [23] have reported that normal skin is consist of three layers: The epidermis (thickness $0.06-0.6 \mathrm{~mm}$ ) on the most external surface; the underlying dermis (thickness 1-4 $\mathrm{mm}$ ) containing of connective tissue, nerves, blood, and lymphatic vessels, gland, mast cells, fibroblasts, histiocytes, etc.; and the subcutaneous tissue (thickness 5-20 mm), mainly made of adipose cells. The epidermis appears as a hyperechoic line in nonglabrous skin, while it is shown as bilaminar hyperechoic and parallel lines in glabrous skin.

The dermis appears as a hyperechoic band, usually less bright than the epidermis, whereas subcutaneous fat layer appears as a hypoechoic with hyperechoic fibrous septa in between [24]. More deeply, the superficial fascia covering the muscular tissues can be seen as a hyperechoic regular line. Raffin et al. [25] have reported high-frequency ultrasound (HFU) imaging with $25 \mathrm{MHz}$ linear probe for cutaneous neurofibroma in patients with neurofibromatosis type 1. They demonstrated HFU imaging of dermal lesion located in 4-6 mm depth [25].

\section{Gray-Scale Ultrasonographic Findings}

There are a few studies focusing on US characteristic of subcutaneous NF in English literature. It has been reported that the lesions were depicted as an oval or round shape with irregular or lobular margins, hypoechogenicity on gray-scale US [26]. The author has previously described that the irregular or lobular margin on US seemed to reflect histological proliferation of collagen and spindle-shaped fibroblasts and indicated that proliferative findings of the margin on US and pathology are caused by the driving force of USP6 transcriptional upregulation behind the high proliferative activity and growth of NF [9]. Given the similarity of cytogenetic nature in both intradermal NF and subcutaneous NF, it is putative that intradermal NF may tend to occur in the region with a thin subcutaneous fat layer such as face, head and neck and, rarely the dorsum of the foot. Figure 1a shows that the lesion is diagnosed by pathologically and immunohistochemically as NF in the dorsum of the foot in a 47-year-old woman. The lesion was seated in the superficial location, close to or in contact with the dermis located in $3.8 \mathrm{~mm}$ depth on gray-scale US. The nodule was oval shape with lobular margin and showed hypoechoic pattern and homogeneous echotexture without posterior echo enhancement (Figure 1a).

\section{Color Doppler Ultrasonographic Findings}

To the best of our knowledge, with respect to the intradermal NF, there is only one report on color and power Doppler US in English literature $[10,18]$. We have previously described intradermal NF with clear blood flow signal within the mass on color Doppler US [18] and also reported characteristic power Doppler sonographic imaging of NF from a dermatological perspective [10]. NF occurs from the surface of the fascia and extends into the cutis. Lee et al. [13] defined superficial-type NF as subcutaneous NF and fascial NF located in the deep fascia (the outer muscle fascia) between the subcutaneous fat layer and the muscle. They mentioned that most showed no substantial vascular flow on color Doppler US. Concerning the intramuscular NF, there are a few reports in English literature. Khuu et al. [26] reported that increased flow signals of internal and peripheral locations were shown in intramuscular NF located in the vastus medialis. Nikolaidis et al. [27] stated that increased flows, which made of both peripheral and central penetrating vessels were shown in NF which was embedded between subcutaneous fat and adjacent brachialis muscle on color Doppler US. It has been also reported that intramuscular NF of right rectus abdominis muscle showed some peripheral vascularity on color Doppler US [28].

The vascular proliferation and dilatation may be pathologically significant and characteristic feature in intradermal NF [29,30], while it is suggested that the dermal layer commonly contains rich capillary vessels [12]. Given the pathological evidence and anatomical reason, the author will emphasize that intradermal NF show blood flow signal on color and power Doppler US. With regards to the subcutaneous and fascial types, substantial blood flow signal was not detected on color Doppler US [13]. While intramuscular NF may tend to show both central and peripheral blood flow signals on color Doppler US [26-28]. Figure $1 \mathrm{~b}$ and $1 \mathrm{c}$ show that the lesion is diagnosed by pathologically and immunohistochemically as NF in the dorsum of the foot in a 47-year-old woman. This case showed clear blood flow signal within the nodule on color Doppler US (Figure 1b) and on Fine Flow (Figure 1c). 

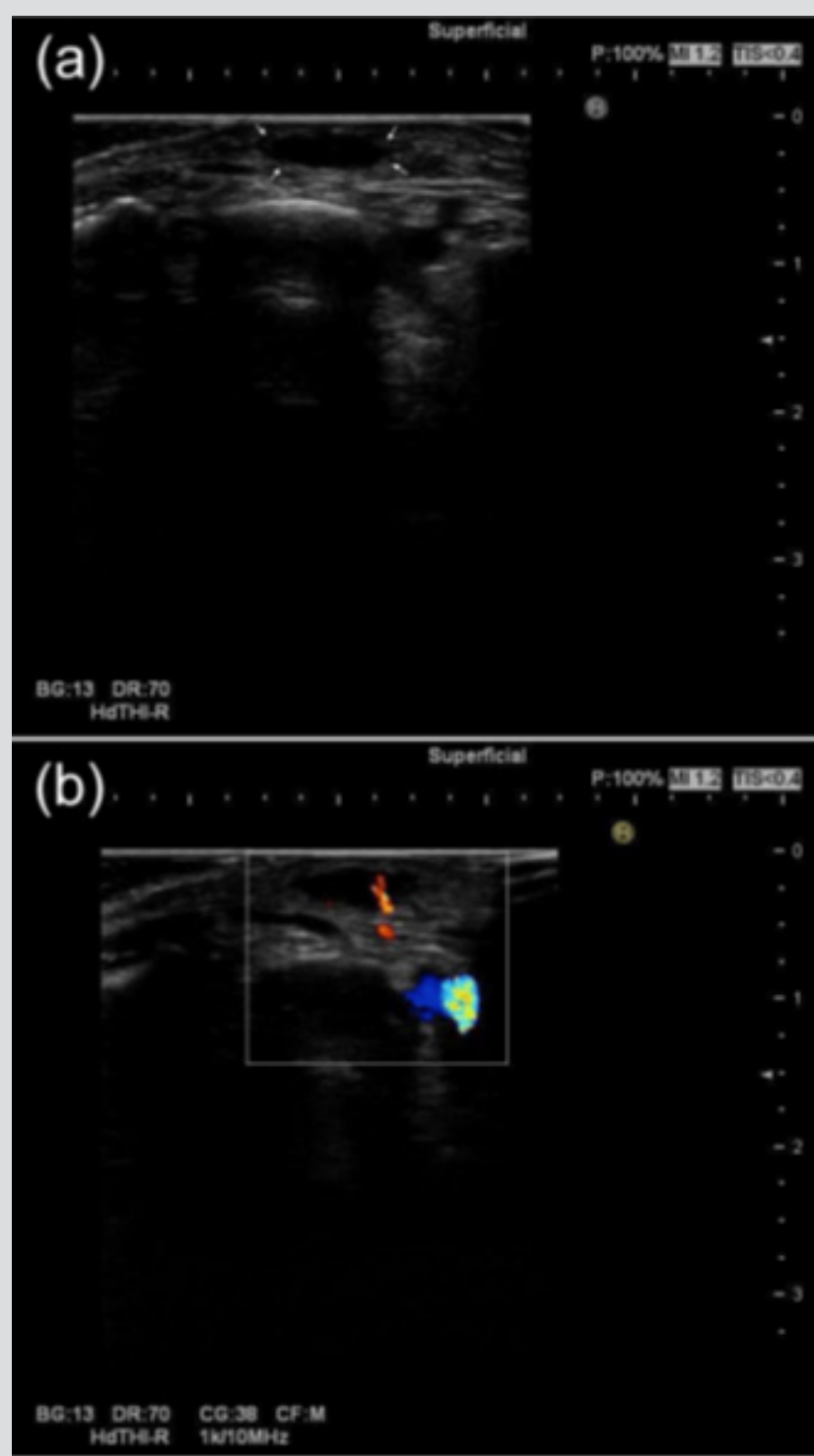

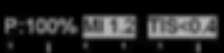

8

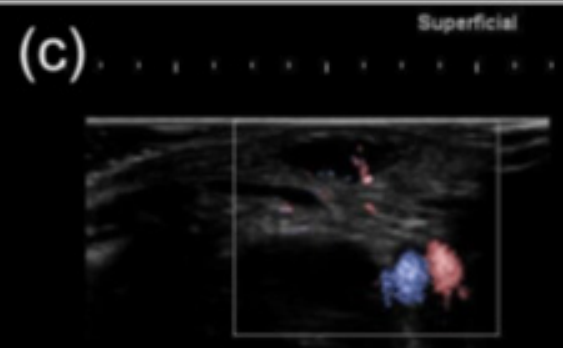

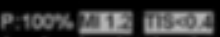

8

Figure 1: Subcutaneous NF, probably in the close to the dermis in the dorsum of the foot in a 47-year-old woman.

(a) Gray-scale US shows a subcutaneous hypoechogenic lesion located in the dorsum of the foot. The shape of nodule is oval with lobular margin.

(b) Blood flow signals within the nodule on color Doppler US are clearly observed.

(c) Blood flow signals within the lesion on Fine Flow are clearly depicted. 


\section{Magnetic Resonance Imaging Findings}

It has been studied that the MR imaging features are variable, reflecting the variable histologic components of the lesions. The mass generally shows nonspecific low-to-intermediate signal intensity on T1-weighted image, while intermediate-to-high signal intensity on T2-weighted image is demonstrated. The fascial tail sign is the important feature on MR imaging, indicating the diagnosis of NF in subcutaneous lesions or the mass in more deeply located tumors $[28,31]$. It has been reported that the inverted target sign may suggestive of the diagnosis in NF [14,32]. Khuu et al. [26] reported the MRI finding of a thin rim of T1 hyperintense signal consistent with fat and also suggested that the appearance of a thin rim may help in making a diagnosis of NF.

\section{Pathological Findings}

Mehregan [33] has suggested that NF is usually composed of a central solid mass with many irregular projections extending outward into the surrounding fat tissue thus resembling a highly invasive growth. It has been indicated that NF typically featured uniform spindled cells arranged in irregularly intersecting short fascicles, and occasional storiform patterns. The cells contained plump, spindled to stellate nuclei with fine to open chromatin and small nucleoli, accompanied by lightly basophilic cytoplasm with ill-defined cytoplasmic borders. The background stroma ranged from myxoid to collagenous. The characteristic tissue culture-like, feathery myxoid appearance was present at least focally [5,9]. Intradermal nodular fasciitis analyzed in a series of 24 cases, showed extravasated red blood cells and scattered lymphocytes and produced particular hemosiderin deposition in $29 \%$ and extensive stromal hemorrhage in $12.5 \%$ [29]. On the basis of the literature $[29,30]$, the author presumes that the features of the blood vessels are of highly diagnostic value in the intradermal nodular fasciitis. Figure 2 show that the lesion is diagnosed by pathologically and immunohistochemically as NF in the dorsum of the foot in a 47-year-old woman. Proliferations of fibroblast-like spindle cells without obvious mitotic changes were seen (Figure 2a). Myxoid change, collagen proliferations and capillary dilatations were seen in the lesion (Figure $2 \mathrm{~b}$ ).

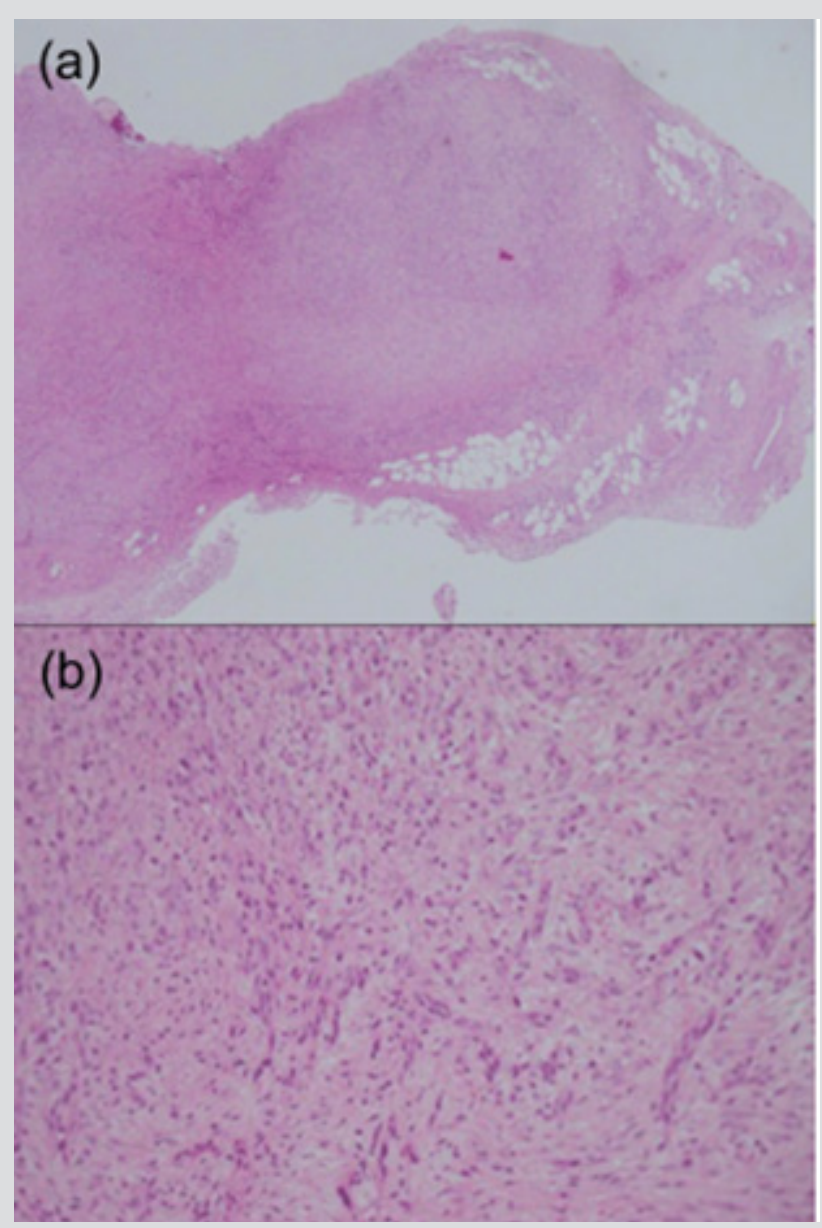

Figure 2: Subcutaneous NF, probably in the close to the dermis in the dorsum of the foot in a 47-year-old woman.

(a) Histopathological finding of the lesion is characterized by the infiltration of fibroblast-like spindle cells in the subcutaneous fatty tissue (hematoxylin and eosin, original magnification X20).

(b) The inside of the nodule shows the immature plump fibroblasts arranged in short irregular bundles and fascicles with a feather-like appearance as well as abundant myxoid changes. Vascular proliferations are observed (hematoxylin and eosin, original magnification X100). 


\section{Immunohistochemical Findings}

It has been Immunohistochemically reported that NF is negative for several markers such as desmin, keratin, or S-100 protein in contrast to sarcoma [34-36], while spindle cells of NF contain vimentin, muscle-specific actin and smooth muscle-specific actin
[35]. Figure 3 show that the lesion is diagnosed by pathologically and immunohistochemically as NF in the dorsum of the foot in a 47-year-old woman. The immunohistochemical staining profile showed smooth muscle actin (SMA) (Figure 3a). Lesion did not stain for desmin (Figure 3b).
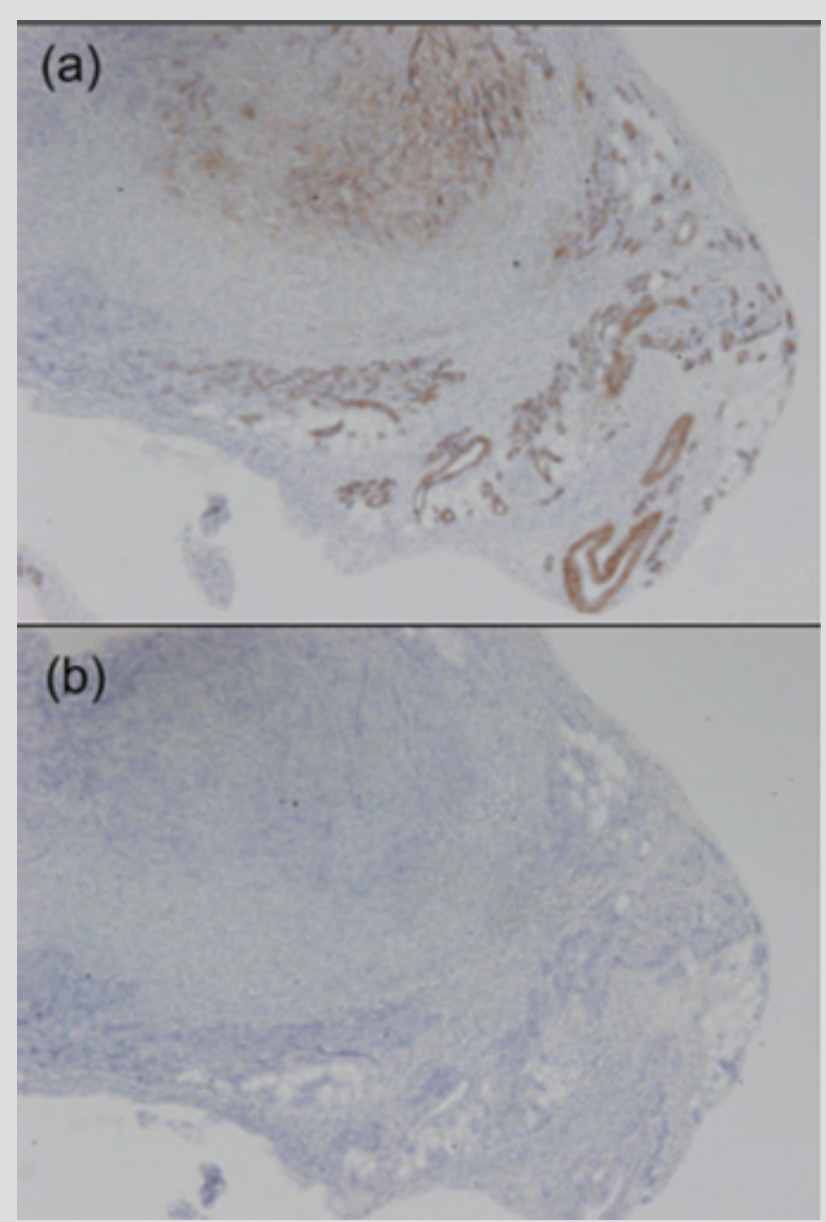

Figure 3: Subcutaneous NF, probably in the close to the dermis in the dorsum of the foot in a 47-year-old woman.

(a) Immunohistochemical finding shows that lesion is positive for smooth muscle actin: original magnification $X 100$.

(b) The lesion is negative for desmin: original magnification X100.

\section{Cytogenetic Findings}

Erickson-Johnson et al. [3] first have reported that NF is as a novel model of transient neoplasia induced by MYH9-USP6 gene fusion. A clear association between NF and a recurrent genetic abnormality has been established in FISH analysis [3-8]. Kumar et al. [4] reported USP rearrangement by FISH in cutaneous NF and suggested that the presence of the USP6 rearrangement and MYH9-USP6 fusion in cutaneous NF cases mirrors what has been reported in more typical subcutaneous presentation of NF. On the basis of these studies [3-8], the similar cytogenetic nature has been demonstrated both subcutaneous NF and intradermal type. The author previously emphasized that proliferative findings of the margin of the nodule on US and pathological features are caused by the driving force of USP6 transcriptional upregulation behind the high proliferative activity and growth of NF from an established cytogenetic nature [9].
Nodular fasciitis occurs from the surface of the fascia and extends into the cutis. Given the similarity of cytogenetic nature in both subcutaneous nodular fasciitis and intradermal type, it is putative that intradermal nodular fasciitis may tend to occur in the region with thin subcutaneous fat layer such as face, head and neck and, rarely the dorsum of the foot. The author suggests that intradermal nodular fasciitis may show blood flow signal within the nodule on color Doppler ultrasonography, because it is due to the reason why the dermal layer contains rich capillary vessels. Subcutaneous nodular fasciitis, especially in a superficial location, possibly close to the dermis may also show blood flow signal on color Doppler. With respects to the intramuscular nodular fasciitis, they tend to grow a large tumor size, it is plausible that blood flow signal within the nodule was detectable on color Doppler ultrasonography. 


\section{Conclusion}

a) It is plausible that intramuscular nodular fasciitis may tend to show blood flow signal on color Doppler ultrasonography.

b) It is putative that intradermal nodular fasciitis may tend to occur in the region with thin subcutaneous fat layer such as face, head and neck.

c) The author suggests that intradermal nodular fasciitis and subcutaneous nodular fasciitis, especially in a superficial location, close to or in contact with the dermis may show blood flow signal on color and power Doppler ultrasonography.

\section{Acknowledgment}

The author deeply appreciates the assistances of Dr. Akira Fujioka, Dr. Minoru Oishi, Dr. Ken Hayashi, Dr. Hikaru Eto and Dr. Masahiro Okada.

\section{Reference}

1. Konwaler BE, Keasbey L, Kaplan L (1955) Subcutaneous pseudosarcomatous fibromatosis (fasciitis). Am J Clin Pathol 25(3): 241-252.

2. Goodlad JR, Fletcher CD (1990) Intradermal variant of nodular 'fasciitis', Histopathology 17(6): 569-571.

3. Erickson Johnson MR, Chou MM, Evers BR, Roth CW, Seys AR, et al (2011) Nodular fasciitis: a novel model of transient neoplasia induced by MYH9-USP6 gene fusion. Lab Invest 91(10): 1427-1433.

4. Kumar E, Patel NR, Demicco EG, Bovee JV, Olivera AM, et al. (2016) Cutaneous nodular fasciitis with genetic analysis: a case series. J Cutan Pathol 43(12): 1143-1149.

5. Shin C, Low I, Ng D, Oei P, Miles C, et al. (2016) USP6 gene rearrangement in nodular fasciitis and histological mimics. Histopathology 69(5): 784791.

6. Erber R, Agaimy A (2018) Misses and near misses in diagnosing nodular fasciitis and morphologically related reactive myofibroblastic proliferations: experience of a referral center with emphasis on frequency of USP6 gene rearrangements. Virchows Arch 473(3): 351360.

7. Patel NR, Chrisinger JSA, Demicco EG, Sarabia SF, Reuther J, et al. (2017) USP6 activation in nodular fasciitis by promoter-swapping gene fusions. Mod Pathol 30(11): 1577-1588.

8. Amary MF, Ye H, Berisha F, Tirabosco R, Presneau N, et al. (2013) Detection of USP6 gene rearrangement in nodular fasciitis: an important diagnostic tool. Virchows Arch 463(1): 97-98.

9. Fujioka K (2018) Presentations of clinical, ultrasonographic and pathological features of nodular fasciitis from an established cytogenetic viewpoint: review of the case series. J Carcinog Mutagen 9(4): 326.

10. Fujioka K, Fujioka A, Tajima S, Oishi M, Hayashi K, et al. (2018) Characteristic power Doppler sonographic imaging of nodular fasciitis from a dermatological perspective: another case and review of three cases. J Clin Case Rep 8(9): 1165

11. Fujioka K, Fujioka A, Oishi M, Hayashi K, Nakayama T (2018) Highresolution ultrasound imaging for angioleiomyoma: a painful and vascularized superficial tumor. Biomed J Sci \& Tec Res 9(5): 7383-7386.

12. Zhang JZ, Zhou J, Zhang ZC (2016) Subcutaneous angioleiomyoma: clinical and sonographic features with histopathologic correlation. J Ultrasound Med 35(8): 1669-1673.

13. Lee KJ, Jin W, Kim GY, Rhee SJ, Park SY, et al. (2015) Sonographic features of superficial-type nodular fasciitis in the musculoskeletal system. J Ultrasound Med 34(8): 1465-1471.
14. Wang XL, De Schepper AM, Vanhoenacker F, De Raeve H, Gielen J, et al. (2002) Nodular fasciitis: correlation of MRI findings and histopathology. Skeletal Radiol 31(3): 155-161.

15. Wortsman X, Alfageme F, Roustan G, Arias Santiago S, Martorell A, et al. (2016) Guidelines for performing dermatologic ultrasound examinations by the DERMUS group. J Ultrasound Med 35(3): 577-580.

16. Wortsman X, Alfageme F, Roustan G, Arias Santiago S, Martorell A, et al. (2016) Proposal for an assessment training program in dermatologic ultrasound by the DERMUS group. J Ultrasound Med 35(11): 2305-2309.

17. Fujioka K, Fujioka A, Eto H, Suzuki K, Sanuki E, et al. (2006) Nodular fascitis in the thigh followed up using ultrasonography. J Med Ultrason 33(1): 49-53.

18. Fujioka K, Fujioka A, Oishi M, Eto H, Tajima S, etal. (2017) Ultrasonography findings of intradermal nodular fasciitis; a rare case report and review of the literature. Clin Exp Dermatol 42(3): 335-336.

19. Fujioka K (2018) Usefulness of comprehensive high-resolution ultrasound imaging in dermatologic field: epidermal cyst. Biomed J Sci \& Tec Res 12(1): 8917-8920.

20. Fujioka K (2019) Painful cutaneous and subcutaneous tumors accompanied with vascularized appearance using high-resolution ultrasound in dermatology: the acronym "ENGLAND" or "LEND AN EGG". Biomed J Sci \& Tec Res 12(4): 9449-9453.

21. Fujioka K (2019) Real- time Tissue elastography in epidermal cyst: along with enhanced MRI and elasticity features of peripheral rim. Biomed J Sci \& Tec Res 16(5): 12310-12314.

22. Fujioka K (2019) A comparison between superficial and deep-seated lipomas on high-resolution ultrasonography: with RTE and MRI appearances. Biomed J Sci \& Tec Res 19(2): 14219-14224.

23. Mandava A, Ravuri PR, Konathan R (2013) High-resolution ultrasound imaging of cutaneous lesions. Indian J Radiol Imaging 23(3): 269-277.

24. Wortsman X (2012) Common applications of dermatologic sonography. J Ultrasound Med 31(1): 97-111.

25. Raffin D, Zaragoza J, Georgescou G, Mourtada Y, Maruani A, et al. (2017) High-frequency ultrasound imaging for cutaneous neurofibroma in patients with neurofibromatosis type 1. EJD 27(3): 260-265.

26. Khuu A, Yablon CM, Jacobson JA, Inyang A, Lucas DR, et al. (2014) Nodular Fasciitis: Characteristic imaging features on sonography and magnetic resonance imaging. J Ultrasound Med 33(4): 565-573.

27. Nikolaidis P, Gabriel HA, Lamba AR, Chan NG (2006) Sonographic appearance of nodular fasciitis. J Ultrasound Med 25(2): 281-285.

28. Mazura JC, Matrai C, Spigland N, Brill PW, Kovanlikaya A (2013) Intramuscular nodular fasciitis of the rectus abdominis muscle in an 11-year-old girl. Skeletal Radiol 42(1): 147-150.

29. de Feraudy S, Fletcher CD (2010) Intradermal nodular fasciitis: a rare lesion analyzed in a series of 24 cases. Am J Surg Pathol 34(9): 13771381.

30. Thompson LD, Fanburg-Smith JC, Wenig BM (2001) Nodular fasciitis of the external ear region: a clinicopathologic study of 50 cases. Ann Diagn Pathol 5(4): 191-198.

31. Kransdorif MJ, Mumphey MD (2006) Imaging of soft tissue tumors. $\left(2^{\text {nd }}\right.$ edn.). Philadelphia, PA: Lippincott Williams \& Wilkins.

32. Coyle J, White LM, Dickson B, Ferguson P, Wunder J, et al. (2013) MRI characteristics of nodular fasciitis of the musculoskeletal system. Skeletal Radiol 42(7): 975-982.

33. Mehregan AH (1966) Nodular fasciitis. Arch Dermatol 93(2): 204-210.

34. Lloyd AA, Witheiler, Menter A (2015) Nodular fasciitis of the lip mucosa: a rare but clinically important entity. Clin Exp Dermatol 40(4): 408-412.

35. Borumandi F, Cascarini l, Mallawaarachchi R, Sandison A (2012) The chameleon in the neck: nodular fasciitis mimicking malignant neck mass of unknown primary. Int J Surg Case Rep 3(10): 501-503.

36. Luna A, Molinari L, Bollea Garlatti LA, Ferrario D, Volonteri V, et al. (2019) Nodular fasciitis, a forgotten entity. Int J Dermatol 58(2): 190-193. 


\section{ISSN: 2574-1241}

DOI: $10.26717 /$ BJSTR.2019.20.003490

Kazumi Fujioka. Biomed J Sci \& Tech Res

(C) This work is licensed under Creative

Submission Link: https://biomedres.us/submit-manuscript.php

$\begin{array}{ll}\text { BIOMEDICAL } & \text { Assets of Publishing with us } \\ \text { RESEARCHES } & \text { Global archiving of articles } \\ \text { - Immediate, unrestricted online access } & \text { - Rigorous Peer Review Process } \\ & \text { - Authors Retain Copyrights }\end{array}$

